\title{
MODEL PERTUMBUHAN DAN HASIL TANAMAN Shorea leprosula PADA SISTEM TEBANG PILIH TANAM JALUR TEKNIK SILIN
}

(Modelling Growth and Yields of Shorea leprosula in the Intensified Selective Cutting and Line Planting System)

\author{
Oleh/By: \\ Wahyudi ${ }^{1)}$ dan/and Sudin Panjaitan ${ }^{2)}$ \\ 1) Staf pengajar pada Jurusan Kehutanan UNPAR \\ 2) Peneliti Madya pada Balai Penelitian Kehutanan Banjarbaru Kalimantan Selatan
}

\begin{abstract}
The Intensified Selective Logging and Lined Planting (ISLLP) silvicultural system can be applied in the logged over forest and low potential forest to improve their productivity. The research was aimed to create modelling of growth and yield of Shorea leprosula plantations in the ISLLP system. The research was conducted at research plots of ISLLP in logged over forest of PT. Gunung Meranti, Central Kalimantan Province. The research plots were divided into three plots of Shorea leprosula plantation that planted in 1994 as plot 1, year 1999 as plot 2 and year 2008 as plot 3 in which consisted of 200 samples of trees, respectively. Data of Shorea leprosula growth were evaluated by Stella 9.0.2 and SPSS 13, and predicted using table of volume and polynomial equations. The research result showed that group polynomial equations estimated cutting cycle at 32 years old with $R^{2}$ value of greater than $95 \%$.
\end{abstract}

Keywords: Intensified selective logging and lined planting system, Shorea leprosula, polynomial equations.

\begin{abstract}
ABSTRAK
Tebang Pilih Tanam Jalur Intensif (TPTJI) merupakan sistem silvikultur yang dapat diterapkan pada hutan bekas tebang dan hutan dengan potensi rendah untuk meningkatkan produktivitas mereka. Penelitian ini bertujuan untuk membuat model pertumbuhan dan hasil tanaman meranti (S. leprosula) yang dikembangkan pada sistem TPTJ Teknik Silin. Penelitian ini dilakukan di plot penelitian TPTJ Teknik Silin di areal bekas tebangan hutan PT. Gunung Meranti, Propinsi Kalimantan Tengah. Plot penelitian ini dibagi menjadi tiga plot tanaman S. leprosula yang masing-masing ditanam pada tahun 1994 (petak 1), tahun 1999 (petak 2) dan tahun 2008 (petak 3) yang terdiri dari 200 sampel pohon. Data pertumbuhan S. leprosula dievaluasi dengan perangkat lunak Stella 9.0.2 dan SPSS 13, dan diprediksi dengan menggunakan tabel volume dan persamaan
\end{abstract}


polinominal. Hasil penelitian menunjukkan bahwa kelompok persamaan polinominal diperkirakan memotong siklus tanaman meranti pada umur 32 tahun dengan nilai R lebih besar dari $95 \%$.

\section{Kata kunci: Sistem Tebang Pilih Tanam Jalur teknik silin, Shorea leprosula, model persamaan polinominal.}

\section{PENDAHULUAN}

\section{A. Latar Belakang}

Meranti adalah salah satu jenis pohon dari famili Dipterocarpaceae yang mendominasi hutan alam di wilayah Indonesia bagian Barat dan Tengah (McKinnon et al. 2000) dengan kualitas kayu yang baik. Jenis ini juga mendominasi realisasi produksi kayu bulat dari hutan alam dan menjadi primadona industri kayu lapis (plywood) dan wood working di era 80-90an (Wahyudi 2009). Dengan demikian pengembangan tanaman meranti untuk meningkatkan produktivitas hutan adalah langkah yang tepat.

Sejalan dengan makin tingginya laju degradasi dan deforestasi di Indonesia, maka pengembangan tanaman meranti menjadi sebuah keharusan, khususnya pada hutan sekunder (logged over forest) dan kawasan hutan yang tidak produktif. Sistem Tebang Pilih Tanam Jalur (TPTJ) telah menerapkan teknik hutan tanaman pada sebagian areal pengelolaannya. Menurut Ditjen BPK (2005) dan Soekotjo (2009) jenis meranti yang mempunyai riap tertinggi seperti Shorea leprosula dapat dikembangkan dalam jalur tanam pada sistem Tebang Pilih Tanam Jalur (TPTJ).

Secara umum, pola pertumbuhan tanaman membentuk grafik sigmoid (Bukhart 2003; Radonja et al. 2003) yang dapat dirumuskan melalui persamaan eksponensial (Brown 1997; Grant et al. 1997; Radonsa et al. 2003) dan polinomial (Porte \& Bartelink 2001; Vanclay 2001). Daur ekonomis tanaman dapat dilihat dari perpotongan antara grafik riap tahunan berjalan (CAI) dan riap tahunan rata-rata (MAI).

Pertumbuhan tanaman dipengaruhi oleh jenis dan genetik (Finkeldey 1989; Hani'in 1999), lingkungan atau tempat tumbuh (Fisher \& Binkley 2000) dan teknik silvikultur (Coates \& Philip 1997; Halle et al. 1978). Faktor lingkungan yang berpengaruh terhadap pertumbuhan tanaman dapat dikelompokkan menjadi dua, yaitu faktor iklim dan faktor tanah. Faktor iklim terdiri dari curah hujan, cahaya, suhu, kelembaban, angin dan letak geografi berdasarkan garis lintang. Sedangkan faktor tanah terdiri dari sifat fisik, kimia dan biologi tanah, kelerengan, aspek, ketinggian dan drainase. 
Sampai dengan tahun 2010 terdapat 29 Izin Usaha pemanfaatan Hasil Hutan Kayu (IUPHHK) yang menerapkan sistem TPTJ (Ditjen BPK 2010) dan menggunakan jenis meranti sebagai tanaman unggulan dalam jalur tanam. Mengingat keberadaannya yang masih relatif baru maka sistem ini masih banyak memerlukan input-input sebagai bagian dari teknik silvikultur dalam rangka memantapkan pelaksanaannya di masa datang. Salah satu input yang cukup penting adalah pemodelan pertumbuhan tanaman meranti di dalam jalur tanam untuk memprediksi pertumbuhan dan hasil yang merupakan gambaran nyata di lapangan. Pemodelan dapat mempermudah kita dalam melakukan evaluasi hasil tanaman dan kemungkinan penerapan rekayasa dan teknik silvikultur yang diperlukan.

\section{B. Tujuan dan Manfaat Penelitian}

Penelitian ini bertujuan untuk menyusun model pertumbuhan tanaman meranti (Shorea leprosula) yang dikembangkan dalam jalur tanam serta memilih model yang paling baik untuk memprediksi pertumbuhan tanaman tersebut. Penelitian diharapkan dapat bermanfaat bagi para pihak (stakeholder), khususnya para pelaksana sistem TPTJ, dalam memprediksi pertumbuhan tanaman dan perolehan hasil pada saat pemanenan.

\section{METODOLOGI PENELITIAN}

\section{A. Lokasi dan Waktu Penelitian}

Penelitian dilaksanakan pada plot-plot penelitian tanaman meranti (Shorea leprosula) dalam jalur yang ditanam tahun 1994 dan 1999 serta pada jalur tanam sistem TPTJ yang ditanam tahun 2008. Semua plot penelitian berada di IUPHHK PT. Gunung Meranti yang terletak di Kecamatan Kapuas Hulu, Kabupaten Kapuas Provinsi Kalimantan Tengah.

Pengambilan data diameter dan tinggi tanaman pada plot 1 dan 2 dilakukan tahun 2010 (umur 11 dan 16 tahun) sedangkan pada plot 3 dilakukan setiap bulan Pebruari tahun 2008, 2009 dan 2010 atau pada saat tanaman berumur 0,1 dan 2 tahun.

\section{B. Metode Penelitian}

1. Penelitian dilakukan pada tiga plot tanaman meranti (Shorea leprosula) dalam jalur tanam masing-masing berukuran $500 \mathrm{~m}$ x $60 \mathrm{~m}\left(=30.000 \mathrm{~m}^{2}\right)$. Lebar jalur tanam 3-5 m dan jarak antar tanaman dalam jalur 2,5 m. Lebar jalur antara $17 \mathrm{~m}$ sehingga jarak tanam keseluruhan 
$20 \mathrm{~m}$ x 2,5 m (Gambar 1). Ketiga plot penelitian mempunyai kondisi tapak yang relatif sama, yaitu jenis tanah podsolik merah kuning dengan struktur tanah gumpal beragregat kurang serta mempunyai permeabilitas yang rendah. Tekstur tanah berupa geluh lempung pasiran dan pada lapisan bawah $(>25 \mathrm{~cm})$ didominasi lempung. Dengan demikian ketiga plot penelitian dianggap mempunyai tapak yang sama serta perlakuan silvikultur yang sama pula berupa pembukaan kanopi secara memanjang.

2. Plot 1 adalah tanaman meranti yang ditanam tahun 1994 (umur 16 tahun), plot 2 ditanam tahun 1999 (umur 11 tahun) dan plot 3 ditanam tahun 2008. Masing-masing plot diambil sample tanaman secara acak sebanyak 200 tanaman.

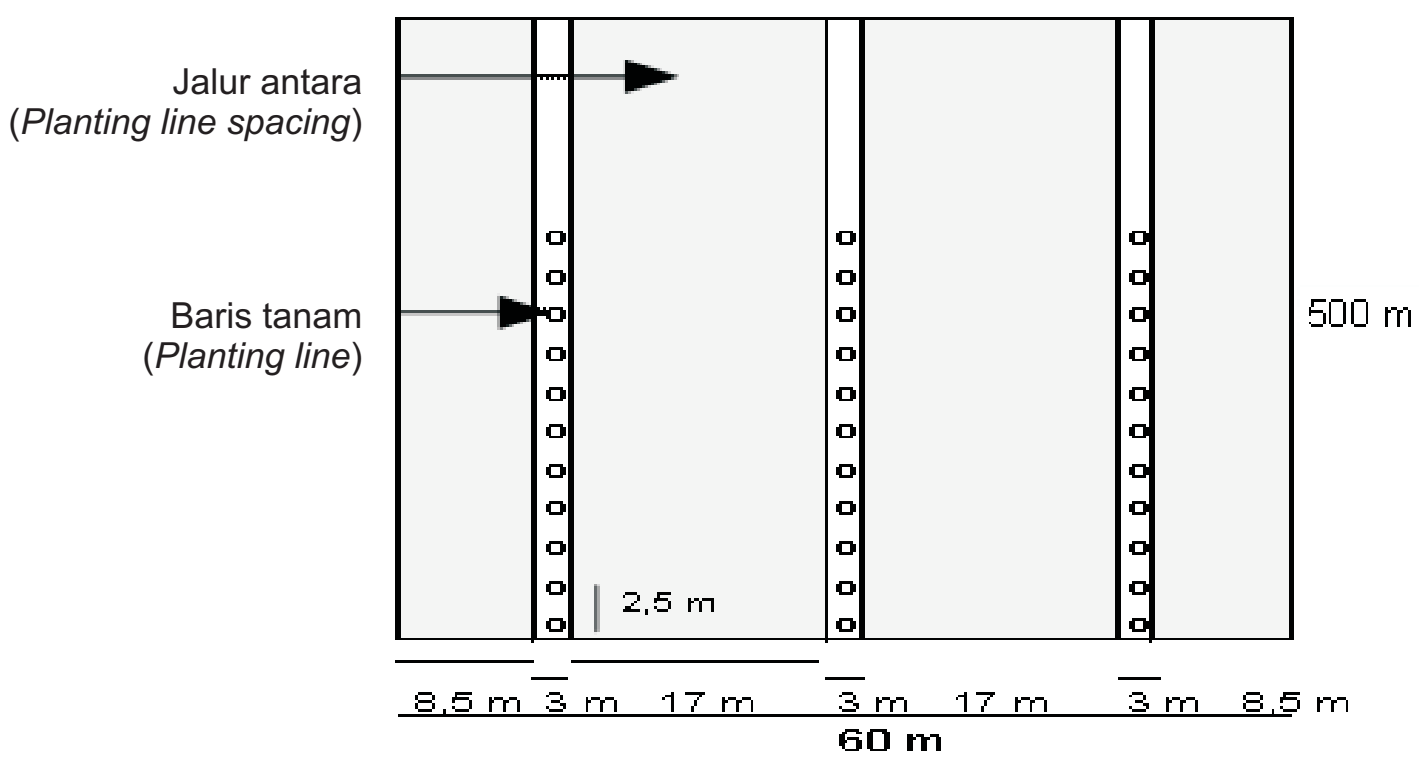

Gambar (Figure) 1. Layout penelitian tanaman meranti dalam jalur tanam sistem TPTJ (Meranti research design in planting line of selective logging \& lined plating system)

3. Pengukuran dilakukan terhadap diameter ( $\mathrm{dbh}$ ) dan tinggi bebas cabang tanaman.

4. Siklus tebang ditentukan pada saat tanaman meranti telah mencapai diameter $50 \mathrm{~cm}$ ke atas (Ditjen BPK 2005, Soekotjo, 2009).

\section{Analisis Data}

Pertumbuhan dan hasil tanaman meranti (Shorea leprosula) diprediksi dengan menggunakan lima kelompok (5 sub model) tanaman berdasarkan riap, yaitu kelompok pertumbuhan sangat lambat, lambat, sedang, cepat dan sangat cepat. Interval riap (5) ditentukan 
melalui formula (Pollet \& Nasrullah 1994) $I_{r}=r_{b}-r_{k} / 5$, dimana: $I_{r}$ : interval berdasarkan riap, $r_{b}$ : riap terbesar, $\mathrm{r}_{\mathrm{k}}$ : riap terkecil. Model-model pertumbuhan tanaman pada lima kelompok tersebut adalah $\mathrm{y}_{\mathrm{i}}=\mathrm{c}_{\mathrm{i} 1}+\mathrm{c}_{\mathrm{i} 2} \mathrm{x}+\mathrm{c}_{\mathrm{i} 3} \mathrm{x}^{2}$ (Porte \& Bartelink 2001; Vanclay 2001) dimana: $\mathrm{y}_{\mathrm{i}}$ : diameter akhir ratarata kelompok ke-i, $\mathrm{x}$ : waktu (tahun) dan $\mathrm{c}_{\mathrm{i} 1}, \mathrm{c}_{\mathrm{i} 2}, \mathrm{c}_{\mathrm{i} 3}$ : konstanta. Perangkat lunak yang digunakan dalam penelitian ini adalah Stella 9.0.2, SPSS.13. dan microsoft exel.

\section{HASIL DAN PEMBAHASAN}

Rekapitulasi hasil pengukuran tanaman meranti (Shorea leprosula) pada plot 1 dan 2 tahun 2010 dan plot 3 tahun 2008, 2009 dan 2010 disajikan dalam Tabel 1.

Tabel (Table) 1. Rekapitulasi hasil pengukuran tanaman meranti (Shorea leprosula) (Recapitulation of meranti measurement)

\begin{tabular}{|c|c|c|c|c|c|c|c|c|}
\hline \multirow{2}{*}{$\begin{array}{l}\text { Data } \\
\text { tahun } \\
\text { (Date) } \\
\text { (year) }\end{array}$} & \multirow{2}{*}{$\begin{array}{c}\text { Umur } \\
\text { (tahun) } \\
\text { (Age) } \\
\text { (year) }\end{array}$} & \multirow{2}{*}{$\begin{array}{c}\text { Jumlah } \\
\text { tanaman } \\
\text { (Number of } \\
\text { trees) }\end{array}$} & \multirow{2}{*}{$\begin{array}{c}\text { Persen } \\
\text { hidup (\%) } \\
\text { (Survived } \\
\text { tree) (\%) }\end{array}$} & \multicolumn{4}{|c|}{ Diameter (Diameter) } & \multirow{2}{*}{$\begin{array}{c}\text { Tinggi } \\
\text { rata2 }(\mathrm{m}) \\
\text { (Average } \\
\text { height) }(\mathrm{m})\end{array}$} \\
\hline & & & & $\operatorname{Min}(\mathbf{c m})$ & $\begin{array}{l}\text { Mak }(\mathrm{cm}) \\
\operatorname{Max}(\mathrm{cm})\end{array}$ & $\begin{array}{c}\text { Rata2 }(\mathrm{cm}) \\
(\text { Average })(\mathrm{cm})\end{array}$ & $\begin{array}{l}\text { MAI }(\mathrm{cm} / \mathrm{th}) \\
\text { MAI }(\mathrm{cm} / \text { year })\end{array}$ & \\
\hline 2008 & 0 & 200 & 100 & 0,30 & 0,66 & 0,50 & 0,00 & 0,35 \\
\hline 2009 & 1 & 200 & 89,50 & 0,36 & 3,62 & 1,05 & 1,08 & 1,50 \\
\hline 2010 & 2 & 200 & 84,2 & 0,40 & 7,14 & 2,13 & 1,08 & 2,80 \\
\hline 2010 & 11 & 200 & 61,87 & 3,10 & 28,23 & 13,50 & 1,25 & 9,20 \\
\hline 2010 & 16 & 200 & 61,21 & 12,91 & 36,42 & 21,22 & 1,36 & 13,10 \\
\hline
\end{tabular}

Tabel 1 menunjukan bahwa riap tahunan rataan (MAI) diameter tanaman meranti (Shorea leprosula) sejak umur pertama sampai umur 16 tahun selalu mengalami peningkatan. Pada umur 16 tahun MAI tanaman meranti (Shorea leprosula) sebesar 1,36 $\mathrm{cm} /$ tahun dengan prosen hidup tanaman sebesar 61,21\%. Tanaman yang ada merupakan hasil seleksi alam dan seleksi dari kegiatan penjarangan. Pada umur tersebut, rata-rata diameter tanaman (Shorea leprosula) sebesar 21,22 cm dengan tinggi 13,1 m. Menurut Wahyudi (2011) pertumbuhan diameter pohon meranti (MAI) akan mengalami peningkatan hingga mencapai titik tertinggi, yaitu pada saat mencapai kelas diameter 30 cm sampai $40 \mathrm{~cm}$ dan selanjutnya akan menurun kembali secara bertahap.

Penentuan persamaan polinomial pada 5 kelompok riap tanaman meranti (Shorea leprosula) (5 sub model) didasarkan pada kecepatan pertumbuhannya (Pollet dan Nasrullah 1994). Sub model 1 adalah pertumbuhan sangat lambat, sub model 2 adalah lambat, sub model 3 adalah sedang, sub model 4 adalah cepat dan sub model 5 adalah sangat cepat. Prosentase pohon yang terdapat pada masing-masing kelompok (sub model) serta bentuk persamaan pertumbuhannya disajikan dalam Tabel 2. 
Tabel(Table) 2. Lima sub model pertumbuhan tanaman berdasarkan kelas riapnya (Five sub models of tree growth based on increment categories/classes)

\begin{tabular}{|c|c|c|c|l|c|c|}
\hline $\begin{array}{c}\text { Kelas } \\
\text { pertumbuhan } \\
\text { (Growth category) }\end{array}$ & $\begin{array}{c}\text { Jumlah } \\
\text { tnm (\%) } \\
\text { (number of } \\
\text { trees) (\%) }\end{array}$ & $\begin{array}{c}\text { Galat } \\
\text { baku } \\
\text { (Standar } \\
\text { error) }\end{array}$ & $\begin{array}{c}\text { MAI } \mathbf{\Phi} \\
\text { (cm/th) } \\
\text { (Mean } \\
\text { annual } \\
\text { increment) } \\
\text { (cm/year) }\end{array}$ & $\begin{array}{c}\text { Persamaan } \\
\text { (Equation) }\end{array}$ & $\begin{array}{c}\text { Koefisien } \\
\text { regresi } \\
\text { (Regression } \\
\text { coefisien) }\end{array}$ \\
\hline Sangat lambat & 17 & 2,09 & 0,69 & $\mathrm{y}=0,0181 \mathrm{x}^{2}+0,3801 \mathrm{x}+0,3627$ & 95,5 & 0,95 \\
Lambat & 26 & 3,13 & 1,16 & $\mathrm{y}=0,0131 \mathrm{x}^{2}+0,8299 \mathrm{x}+0,4547$ & 97,9 & 0,98 \\
Sedang & 27 & 6,25 & 1,63 & $\mathrm{y}=-0,0023 \mathrm{x}^{2}+1,3906 \mathrm{x}+0,5198$ & 99,1 & 0,99 \\
Cepat & 26 & 8,42 & 1,89 & $\mathrm{y}=-0,0217 \mathrm{x}^{2}+2,0425 \mathrm{x}+0,5739$ & 99,6 & 0,99 \\
Sangat cepat & 4 & 11,87 & 2,30 & $\mathrm{y}=-0,0339 \mathrm{x}^{2}+2,6408 \mathrm{x}+0,6353$ & 99,5 & 0,99 \\
\hline
\end{tabular}

Berdasarkan Tabel 2 terlihat bahwa sebagian besar tanaman berada pada kelompok sub model pertumbuhan sedang dengan prosentase $27 \%$, menyusul sub model kelompok pertumbuhan lambat dan cepat masing-masing $26 \%$. Sub model kelompok pertumbuhan sangat cepat yang mempunyai tingkat pertumbuhan tertinggi hanya berada pada urutan terakhir dengan prosentase $4 \%$. Diperkirakan jumlah tanaman Shorea leprosula yang mempunyai diameter terbesar pada akhir daur hanya sebesar $4 \%$ tersebut, menyusul kelompok di bawahnya sebesar $26 \%$ dan seterusnya. Semua persamaan yang dihasilkan mempunyai nilai koefisien determinasi di atas 95\%. Model ini cenderung mengarahkan pencapaian diameter tanaman meranti (Shorea leprosula) sebesar $50 \mathrm{~cm}$ ke atas $(50,43 \mathrm{~cm})$ pada umur 32 tahun (Gambar 2).

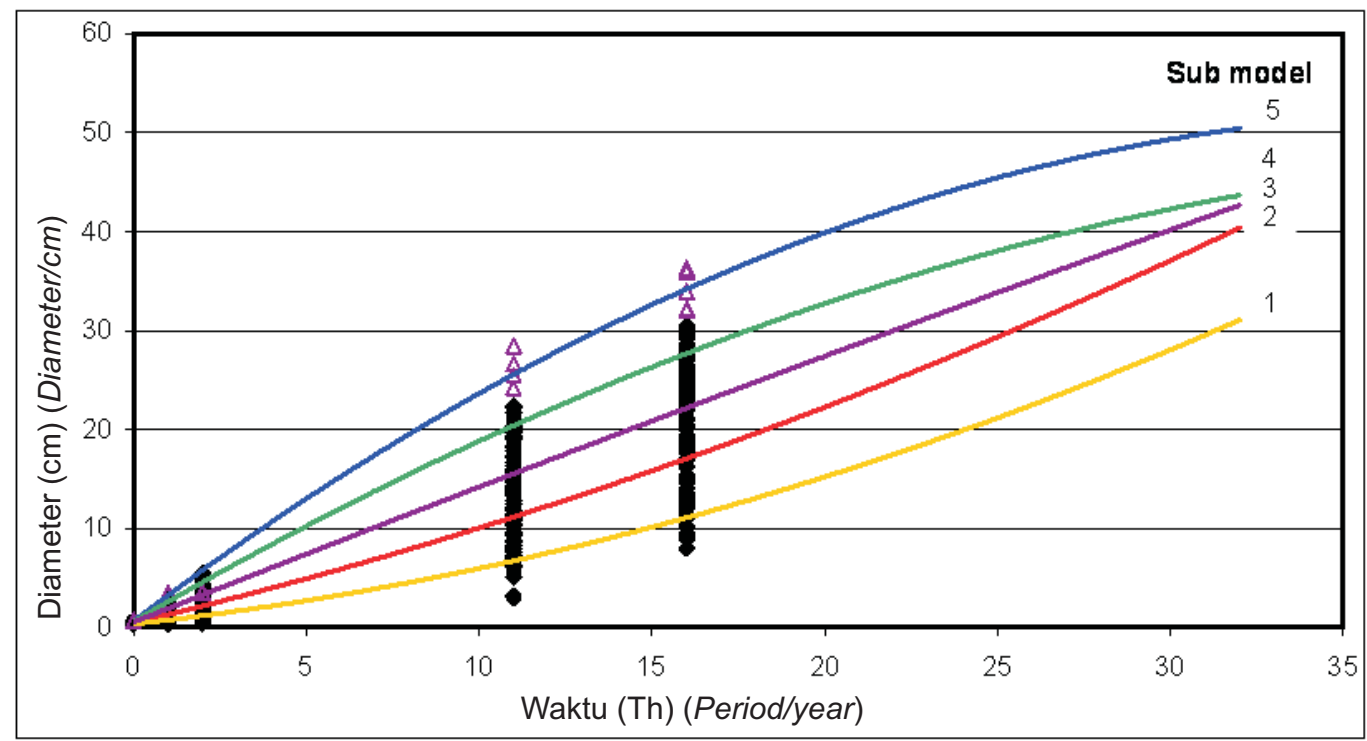

Gambar(Figure) 2. Pertumbuhan diameter shorea leprosula pada lima sub model pertumbuhan (Diameter growth of $\mathrm{S}$. leprosula in 5 sub models of growth) 
Tingkat pertumbuhan setiap individu pohon dalam tegakan hutan seumur (even-aged stand forest) dan tidak seumur (uneven-aged stand forets) selalu berbeda. Pendekatan umum menggunakan model tegakan harus mencermati penyimpangan (koefisien variasi) yang selalu muncul dalam setiap persamaan. Makin besar keragaman populasi yang diteliti akan semakin besar pula penyimpangan yang didapatkan sehingga dapat mengurangi akurasi prediksi.

Untuk memperkecil penyimpangan yang ada maka perhitungan dinamika tegakan dapat dipecah dalam beberapa kelompok tanaman berdasarkan tingkat pertumbuhannya. Pemodelan individu pohon atau kelompok pohon telah banyak dilakukan dengan mendasarkan pada bermacammacam fungsi. Rodriguez et al. (2003) menggunakan sub model pertumbuhan pohon Populus euramericana pada hutan seumur monoculture berdasarkan kelas tapak. Vanclay (1995) dan Radonsa et al. (2003) menyebutkan adanya pengelompokan dalam pemodelan kelas tegakan (sub model) berdasarkan kerapatan, tapak dan lain-lain.

Sering ditemukan adanya hutan tanaman seumur (monoculture) yang tumbuh pada kondisi tapak dan kerapatan yang relatif seragam, namun tetap dijumpai adanya perbedaan pola pertumbuhan pada masing-masing individu atau kelompok individu penyusun tegakan tersebut. Beberapa unit manajemen menyiasati fenomena ini dengan melakukan penjarangan agar terbentuk tegakan yang lebih seragam. Apabila jenis tanaman, kondisi lingkungan dan perlakuan silvikultur sama atau telah dianggap sama, maka perbedaan pola pertumbuhan pada masing-masing individu atau kelompok individu tersebut disebabkan oleh faktor genetik (Finkeldey, 1989), yang dikumulatifkan dengan kondisi lingkungan sebagai akibat dinamika tegakan yang terbentuk kemudian.

Dengan berasumsi pada logika dan fenomena di atas, maka pemodelan tanaman dalam jalur tanam pada sistem TPTJ lebih sesuai menggunakan model kelompok tanaman berdasarkan kenampakan (phenotype) awal berupa kecepatan pertumbuhan diameter dan tinggi masing-masing.

\section{KESIMPULAN DAN SARAN}

1. Model pertumbuhan tanaman dengan pola polinomial yang dipisahkan dalam lima kelompok sub model cenderung mengarahkan pertumbuhan dan hasil tanaman meranti (Shorea leprosula) dalam jalur tanam pada sistem silvikultur Tebang Pilih Tanam Jalur (TPTJ) teknik silin pada umur 32 tahun dengan nilai koefisen determinasi di atas 95\%.

2. Sistem silvikultur Tebang Pilih Tanam Jalur teknik silin sebaiknya menggunakan daur selama 32 tahun atau lebih (misalnya 35 tahun) untuk mendapatkan manfaat yang optimal bagi pengelolaan hutan lestari. 


\section{DAFTAR PUSTAKA}

Bettinger P, Boston K, Siry JP, Grebner D.L., 2009. Forest management and planning. Academic Press-Elsevier.

Brown S., 1997. Estimating biomass change of tropical forest a primer. FAO Forestry Paper No.134. FAOUSA.

Burkhart H.E., 2003. Suggestion for choosing an appropriate level for modelling forest stand. In Amaro A, Reed D, Soares P, editors. Modelling Forest System. CABI Publishing.

Coates K.D, Philip JB., 1997. A gap-based approach for development of silvicultural system to address ecosystem management objectives. Journal Forest Ecology and Management 99 (1997) 337-35.

Ditjen BPK, Direktorat Jenderal Bina Produksi Kehutanan. 2005. Keputusan Direktur Jenderal Bina Produksi Kehutanan Nomor SK.226/VI-BPHA/2005 Tentang Pedoman Tebang Pilih Tanam Indonesia Intensif(Silin). Departemen Kehutanan, Jakarta.

Ditjen BPK, Direktorat Jenderal Bina Produksi Kehutanan. 2010. Surat Keputusan Direktur Jenderal Bina Produksi Kehutanan No. SK.31/VI-BPHA/2010 tentang Penunjukan Pemegang IUPHHK pada Hutan Alam sebagai Pelaksana Silvikultur TPTJ dengan teknik Silin. Ditjen Bina Produksi Kehutanan, Jakarta.

Finkeldey R., 1989. An Introduction to Tropical Forest Genetic. Institute of Forest Genetics and Forest Tree Breeding, Goettingen, Germany.

Fisher R.F, Binkley., 2000. Ecology and Management of Forest Soil. Third Edition. John Wiley \& Sons, Inc., New York.

Fyllas N.M, Politi P.I, Galanidis A, Dimitrakopoulo P.G, Arianoutsou M., 2010. Simulating regeneration and vegetation dynamics in Mediterranean Coniferous Forest. Ecology Modelling Journal. 34.

Gadow K. V, Hui G., 1999. Modelling Forest Development. Kluwer Acamedmic Publishers.

Grant W.E, Pedersen E.K, Marin S.L. 1997. Ecology and Natural Resource Management. Systems Analysis and Simulation. John Wiley \& Sons, Inc.

Halle F, Oldeman R.A.A, Tomlinson P.B. 1978. Tropical Trees and Forest, An Architectural Analysis. Springer Verlag Berlin-Heidelberg-New York. 
Hani'in O., 1999. Pemuliaan pohon hutan Indonesia menghadapi tantangan abad 21. Dalam Hardiyanto EB, editor. Prosiding Seminar Nasional Status Silvikultur 1999. Peluang dan Tantangan Menuju Produktifitas dan Kelestarian Sumberdaya Hutan Jangka Panjang. Wanagama I. Fakultas Kehutanan UGM, Yogyakarta.

Kozlowski T.T, Pallardy S.G., 1997. Physiology of Woody Plants. Academic Press.

MacKinnon K, Hatta G, Hakimah H, Arthur M., 2000. Ekologi Kalimantan. Seri Ekologi Indonesia, Buku III. Canadian International Development Agency (CIDA), Prenhallindo, Jakarta.

Pollet A, Nasrullah, 1994. Penggunaan Metode Statistika untuk Ilmu Hayati. Gadjah Mada University Press, Yogyakarta.

Porte A, Bartelink H.H. 2001. Modelling mixed forest growth: a review of models for forest management. Eco. Model. Journal.

Radonsa P.J, Koprivica M.J, Lavadinovic V.S. 2003. Modelling current annual height increment of young Douglas-fir stands at different site. In Amaro A, Reed D, Soares P, editors. Modelling Forest System. CABI Publishing.

Rodriguez F, De La Rosa JA, Aunos A., 2003. Modelling the diameter at breast height growht of Populus euramericana plantation timber in Spain. In Amaro A, Reed D, Soares P, editors. Modelling Forest System. CABI Publishing.

Soekotjo, 2009. Teknik Silvikultur Intensif(Silin). Gadjah Mada University Press.

Vanclay, J.K., 1995. Growth models for tropical forest: A synthesis of models and methods.

Royal Veterinary and Agricultural University.Thorvaldsensvej 57. DK-1871 Frederiksberg, Denmark.

Vanclay J.K., 2001. Modelling Forest Growth and Yield. Applications to Mixed Tropical Forest. CABI Publishing.

Wahyudi, 2009. Selective cutting and line enrichment planting silvicultural system development on Indonesian tropical rain forest. In: GAFORN-International Summer School, Geor-August Universität Göttingen and Universität Dresden, Germany. 
Vol.5 No.2, Desember 2011

Wahyudi, 2011. Perkembangan tanaman dan tegakan tinggal pada sistem Tebang Pilih Tanam Indonesia Intensif. (Disertasi). Bogor: Program Pascasarjana, IPB. 